\title{
POTENSI PENGGUNAAN PARASITOID DALAM PENGENDALIAN LALAT BUAH Bactrocera DI PULAU LOMBOK
}

\author{
Akhmad Sukri ${ }^{1}$, Gito Hadi Prayitno ${ }^{2}$ \\ ${ }^{1}$ Institut Keguruan dan Ilmu Pendidikan Mataram, ${ }^{2}$ Universitas Mataram \\ email:sukri_bio04@yahoo.co.id
}

\begin{abstract}
ABSTRAK
Penelitian ini bertujuan untuk mendeskripsikan potensi penggunaan parasitoid dalam pengendalian lalat buah Bactrocera di Pulau Lombok. Data atau informasi diperoleh melalui kajian pustaka (studi referensi). Hasil kajian pustaka menunjukkan bahwa di Pulau Lombok telah ditemukan beberapa spesies lalat buah dari genus Bactrocera yang menyerang beberapa jenis buah yaitu mangga, jambu air dan belimbing. Ditemukannya beberapa jenis parasitoid dari lalat buah yaitu Biosteres vandenboschi Fullaway, Opius makii Sonan, Chalcidoidea, Eurytomide, Diapriidae dan Eulophidae di Pulau Lombok dapat digunakan untuk pengendalian populasi lalat buah. Konsep penggunaan parasitoid dalam mengendalikan populasi lalat buah dapat diterapkan melalui tahapan berikut: isolasi parasitoid, pengembangan parasitoid dan pelepasan ke alam.
\end{abstract}

Kata kunci: Parasitoid, lalat buah Bactrocera

\section{PENDAHULUAN}

Konsumen seringkali mengalami kekecewaan dalam membeli buah. Hal ini disebabkan karena buah yang dibelinya tampak bagus dan mulus dari luar, tetapi setelah buahnya dikupas ternyata mengandung ulat sehingga menyebabkan buah yang dibeli tidak bisa dikonsumsi. Salah satu hama yang dapat menimbulkan kerusakan pada buah adalah lalat buah.

Lalat buah merupakan salah satu hama yang sangat ganas pada tanaman hortikultura di dunia. Lebih dari 100 jenis

Intensitas gangguan atau serangan lalat buah pada buah dapat mencapai $100 \%$ untuk setiap kali panen pada populasi yang cukup tinggi. Satu ekor lalat buah dapat merusak 140 buah dalam sehari dengan kerugian yang ditimbulkan oleh lalat buah di perkebunan dapat mencapai $10-40 \%$ untuk satu macam buah saja. Bila lalat buah ini dibiarkan berkembang terus dapat merugikan petani buah akibat dari kerusakan yang ditimbulkan oleh lalat buah, sehingga terjadi penurunan jumlah hasil panen buah-buahan (Putra, 1997).

Artayasa dan Gito (2003), telah berhasil mengidentifikasi spesies dan inang lalat buah tanaman hortikultura dapat diserang oleh lalat buah (Kuswadi, 2005). Menurut Widarto (1996), lebih dari $75 \%$ jenis tanaman yang dibudidayakan di Indonesia terserang oleh lalat buah. Di Indonesia saat ini dilaporkan ada 66 spesies lalat buah, tetapi baru beberapa spesies yang sudah diketahui tanaman inangnya. Dari 130 genus lalat buah yang ditemukan di Indonesia, lalat buah Bactrocera (Daccus) merupakan genus dari lalat buah yang paling berperan dalam penurunan nilai ekonomis buah-buahan (Subahar, 1999).

pada 19 spesies buah yang ditemukan di Lingsar Lombok Barat. Dari hasil tersebut ditemukan satu spesies lalat buah yaitu Bactrocera cucurbitae Coquillet yang menyerang buah pare dan satu spesies lalat buah lainnya yaitu Bactrocera dorsalis Kompleks yang ditemukan menyerang buah mangga, jambu biji, tomat, belimbing, nangka dan cabe. Mulyono (2003), melakukan penelitian yang sama dan telah berhasil menemukan spesies lalat buah pada buah yang diperdagangkan di Pasar Bertais, Kotamadya Mataram. Spesies-spesies lalat buah tesebut adalah Bactrocera carambolae, Bactrocera dorsalis dan Bactrocera cucurbitae yang 
merusak 12 jenis dari 16 jenis buah yang diteliti. Selanjutnya Rauhun (2006), telah berhasil mengidentifikasi spesies Bactrocera yang terdapat pada buah yang diperdagangkan di Pasar Buah Narmada (Lombok Barat) dan Cakranegara (Mataram), hasil penelitiannya diperoleh 5 spesies Bactrocera yaitu Bactrocera dorsalis, Bactrocera carambolae, Bactrocera lombokensis, Bactrocera affinidorsalis dan Bactrocera albistrigata.

Dalam upaya menanggulangi serangan lalat buah terhadap buah-buahan, maka hal yang utama dilakukan adalah mengendalikan populasi hama pada tingkat yang tidak menyebabkan kerugian secara ekonomi. Pengendalaian lalat buah dengan menggunakan pestisida kimia selain harganya mahal juga banyak mencemari lingkungan, terlebih lagi jika penggunaannya kurang bijaksana dan tidak sesuai anjuran, karena bahan kimia dapat membahayakan kesehatan orang yang mengkonsumsi buah tersebut. Pengendalian lalat buah yang lain dilakukan dengan pembungkusan, namun demikian pembungkusan buah ini dinilai kurang efektif. Selain banyaknya bungkus yang digunakan untuk membungkus buah, tidak semua buah bisa dibungkus untuk menghindari serangan lalat buah terutama karena letak buah yang sulit dijangkau. Sehubungan dengan hal tersebut, perlu dilakukan pengendalian hama lalat buah dengan sistem pengendalian terpadu. Salah satu cara dalam pengendalian hama terpadu dapat dilakukan dengan menggunakan musuh alami berupa parasitoid (organisme yang hidup dalam habitat inangnya) yang nantinya akan menekan populasi lalat buah dan bersifat ramah lingkungan.

Malaysia telah banyak memanfaatkan parasitoid dari famili Braconidae yang mempunyai potensi parasitasi sebesar 57\%, sedangkan di Italia potensinya $80-90 \%$. Parasitoid yang telah diidentifikasi di Indonesia adalah Biosteres sp, yang terdapat pada mangga, belimbing dan jambu biji dengan tingkat parasitasi $6-11 \%$, sedangkan
Opius sp banyak ditemukan pada lalat yang menyerang mangga dengan tingkat parasitasi mencapai 7\% (Kuswadi, 2005).

Bukti lain yang menyatakan bahwa parasitoid mempunyai potensi dalam pengendalian hayati lalat buah yaitu kematian pupa lalat buah yang berasal dari buah belimbing (Averhoa carambola) adalah sebesar 60,72\% (koleksi '94) dan 49,58\% (koleksi '95). Pada pupa yang berasal dari buah mangga (Mangifera $s p$ ) kematian pupa lalat buah sebesar 76,84\% (koleksi '94). Kematian pupa lalat buah yang berasal dai jambu air (Sizygium aquaeum) adalah sebesar 63,29\% dan dari buah jambu batu (Psidium guajava) sebesar 69,89\% (koleksi '94) dan 79,18\% (koleksi '95)(Subahar, 1999).

Melihat potensi yang dimiliki parasitoid di atas, maka penggalian informasi tentang potensi penggunaan parasitoid dalam pengendalian lalat buah Bactrocera di Pulau Lombok perlu dilakukan yang pada akhirnya diharapkan dapat meningkatkan jumlah dan mutu produksi buah-buahan di Lombok, sehingga mampu bersaing dengan pasar global.

Tujuan yang ingin dicapai dalam penulisan ini adalah untuk mendeskripsikan potensi penggunaan parasitoid dalam pengendalian lalat buah Bactrocera di Pulau Lombok, sedangkan manfaat penulisan ini adalah memberikan informasi tentang potensi penggunaan parasitoid dalam pengendalian lalat buah Bactrocera di Pulau Lombok. Informasi yang berkaitan dengan penggunaan parasitoid ini dapat dijadikan sebagai bahan masukan untuk membuat suatu kebijakan dalam pengendalian hama lalat buah secara terpadu, sehingga kualitas dan kuantitas produksi buah-buahan yang ada di Pulau Lombok dapat ditingkatkan.

\section{HASIL DAN PEMBAHASAN}

Berdasarkan hasil penelitian Rauhun (2006), ada 5 spesies lalat buah Bactrocera yang berhasil ditemukan di Pasar Buah Narmada dan Cakranegara yaitu Bactrocera 
dorsalis Hendel, Bactrocera carambolae sp.n., Bactrocera lombokensis sp.n., Bactrocera affinidorsalis sp.n. dan Bactrocera albistrigata de Meijere. Beberapa jenis lalat buah ini juga ditemukan di daerah-daerah lain seperti di Jawa, seperti penelitian yang dilakukan oleh Artayasa (1999) pada buah belimbing. Dengan ditemukannya lalat buah Bactrocera carambolae di Lombok, maka tidak menutup kemungkinan lalat buah ini akan menyerang dan merusak jenis buah yang sama seperti yang dilaporkan oleh Artayasa di Subang Jawa Barat.

Parasitoid yang telah ditemukan sekarang ini seperti di Pulau Jawa dan Kalimantan telah diketahui memiliki kemampuam memparasitasi pada jenis lalat buah yang sama seperti parasitoid Opius makii yang mempunyai daerah distribusi di pulau Jawa, memiliki kemampuan memparasitasi lalat buah Bactrocera dorsalis, begitu jaga dengan parasitoid Opius incisii dengan daerah distribusi Kalimantan memiliki kemampuan memparasitasi lalat buah Bactrocera dorsalis.
Beberapa parasitoid yang menyerang Bactrocera juga ditemukan di Lombok (Ardiasningsih, 2006). Enam spesies parasitoid yang berhasil diidentifikasi terdapat pada beberapa jenis buah yaitu belimbing, jambu air dan mangga. Spesies parasitoid Biosteres vandenboschi Fullaway (Bv) terdapat pada buah belimbing dan jambu air, Opius makii Sonan (Op) dan parasitoid Chalcidoidea $(\mathrm{Ch})$ terdapat pada buah belimbing, Eurytomide (Eu) ditemukan pada buah belimbing, jambu air dan mangga, sedangkan Diapriidae (Dp) dan Eulophidae (Ep) terdapat pada buah mangga. Intensitas parasitasi pada tiap jenis buah yang diteliti adalah $4 \%$ pada buah jambu air, $16,71 \%$ pada buah belimbing, serta $56,26 \%$ pada buah mangga seperti pada Tabel 1. Intensitas parasitasi secara keseluruhan dari parasitoid yang terdapat pada buah diperoleh bahwa parasitoid Biosteres vandenboschi (Fullaway) memiliki intensitas parasitasi paling tinggi dari parasitoid lainnya yaitu 7,33\% sedangkan intensitas paling rendah adalah oleh parasitoid Eulophidae yaitu 0,6\% seperti pada Tabel 2 .

Tabel 1 Intensitas parasitasi pada tiap jenis buah yang diperdagangkan di Pasar Buah Narmada dan Cakranegara (Bv: Biosteres vandenboschi Fullaway, Op: Opius makii Sonan, Ch: Chalcidoidea, Eu: Eurytomide, Dp: Diapriidae, Ep: Eulophidae)

\begin{tabular}{|c|c|c|c|c|c|c|c|c|c|}
\hline \multirow{2}{*}{ No } & \multirow{2}{*}{ Lokasi } & \multirow{2}{*}{ Jenis Buah } & \multicolumn{7}{|c|}{ Intensitas parasitasi (\%) } \\
\hline & & & $\mathrm{Bv}$ & Op & $\mathrm{Ch}$ & $\mathrm{Eu}$ & Dp & Ep & Total \\
\hline 1 & Narmada & Belimbing & 9,36 & 1,10 & 1,65 & 4,60 & 0 & 0 & 16,17 \\
\hline \multirow[b]{2}{*}{2} & Cakra & Jambu air & 1 & 0 & 0 & 3 & 0 & 0 & 4 \\
\hline & Negara & Mangga & 0 & 0 & 0 & 17,2 & 32,81 & 6,25 & 56,26 \\
\hline
\end{tabular}

Sumber: Artayasa et al, 2006

Tabel 2 Intensitas parasitasi keseluruhan buah di Pasar Buah Narmada dan Cakranegara

\begin{tabular}{llc}
\hline No & Jenis Parasitoid & Intensitas Parasitasi (\%) \\
\hline 1 & Biosteres vandenboschi Fullaway & 7,33 \\
2 & Eurytomydae & 5,50 \\
3 & Diapriidae & 2,96 \\
4 & Chalcidoidea & 1,30 \\
5 & Opius makii Sonan & 0,85 \\
6 & Eulophidae & 0,60 \\
\hline Total & & 18,54 \\
\hline
\end{tabular}

Sumber: Artayasa et al, 2006 
Besarnya persen parasitasi yang diperoleh akan dapat mengimplikasikan besarnya kontribusi parasitoid dalam menekan atau mengatur populasi inangnya. Melihat potensi kerusakan yang diakibatkan oleh lalat buah pada buah seperti jambu air, mangga dan belimbing, maka prioritas utama pengembangan parasitoid di Pulau Lombok ditujukan untuk pengendalian populasi hama lalat buah yang menyerang buah tersebut.
Namun yang menjadi tantangan adalah bagaimana mengembangkan dan meningkatkan parasitoid yang ada sehingga dapat dimanfaatkan oleh masyarakat menjadi agen pengendali lalat buah yang efektif dan ekonomis. Konsep penggunaan parasitoid dalam mengendalikan populasi lalat buah dapat diterapkan melalui tahapan pada Gambar 1 berikut.

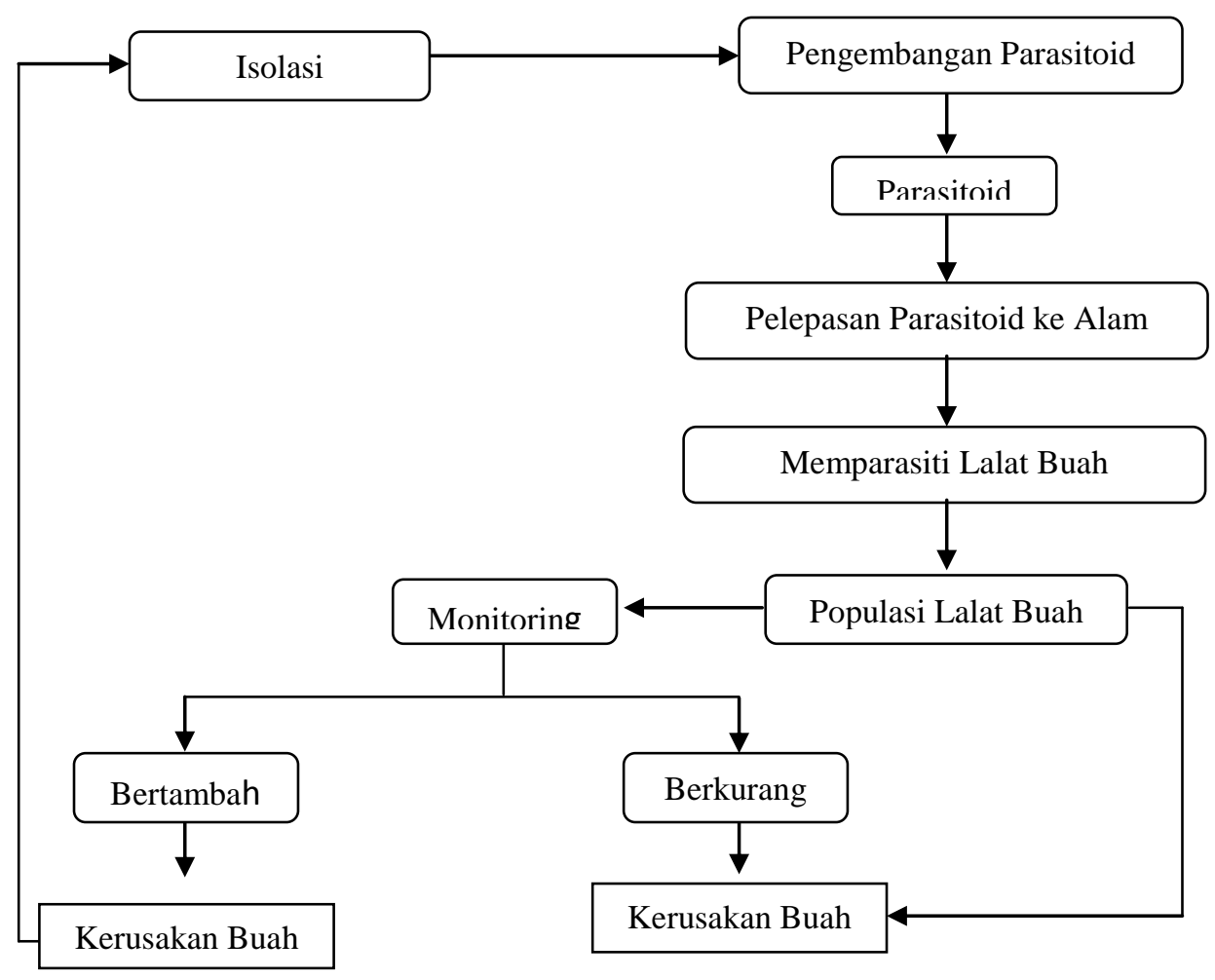

Gambar 1 Skema Penggunaan Parasitoid

Isolasi parasitoid dapat dilakukan dengan mengambil atau mengumpulkan buah yang sudah masak yang mengandung telur dan larva lalat buah Bactrocera, dengan melihat tanda-tanda buah seperti buah yang busuk atau tanda tusukan dari ovipositor lalat buah. Buah yang sudah diambil di masukkan ke dalam ember plastik, kemudian ditutup dengan kain kasa atau sifon, di dalam ember diberi pasir sebagai penampung larva yang keluar dari buah dan sebagai media pupasi (perubahan larva menjadi pupa). Setelah 10 hari pupa yang terdapat dalam pasir diambil. Pupa diletakkan dalam gelas kecil kemudian di letakkan dalam kandang serangga sampai muncul serangga dewasa (lalat buah atau parasitoid). Pupa yang tidak diparasiti akan menjadi lalat buah dewasa, sementara yang diparasiti oleh parasitoid akan menjadi parasitoid dewasa.

Lalat buah yang didapatkan dipisahkan dengan parasitoid. Parasitoid dewasa kemudian dipelihara dengan memberikan air dan madu. Untuk mengembangkan parasitotid, dapat dilakukan dengan memasukkan buah yang telah mengandung telur atu larva lalat buah ke dalam kandang parasitoid, maka akan 
didapatkan buah yang telah mengandung parasitoid. Setelah parasitoid didapatkan, maka parasitoid yang diperoleh dilepaskan ke alam atau ke kebun yang berdasarkan hasil monitoring di lahan tesebut terdapat lalat buah dengan kemelimpahan tinggi. Dengan demikian, parasitoid yang telah dilepas ini akan memparasiti lalat buah, sehingga akan berdampak pada penurunan populasi lalat buah dan akhirnya kerusakan buah berkurang.

Waktu pelepasan parasitoid ke lapangan dilakukan dengan ketentuan apabila populasi lalat buah melebihi ambang ekonomi maka pelepasan (introduksi) parasitoid dilakukan, namun jika populasi lalat buah dibawah ambang ekonomi maka pelepasan parasitoid tidak perlu dilakukan. Ambang ekonomi terjadi jika biaya penanggulangan lalat buah sama dengan hasil produksi buah. Monitoring populasi lalat buah sebagai acuan dalam pelepasan parasitoid, dapat dilihat pada Gambar 2.

Apabila mekanisme seperti grafik di atas berjalan, maka akan terjadi penurunan jumlah populasi lalat buah sehingga kerusakan yang ditimbulkannya menjadi berkurang. Dengan demikian, penggunaan parasitoid sebagai agen pengendali lalat buah Bactrocera diharapkan akan menguntungkan baik secara ekonomis maupun secara ekologis.

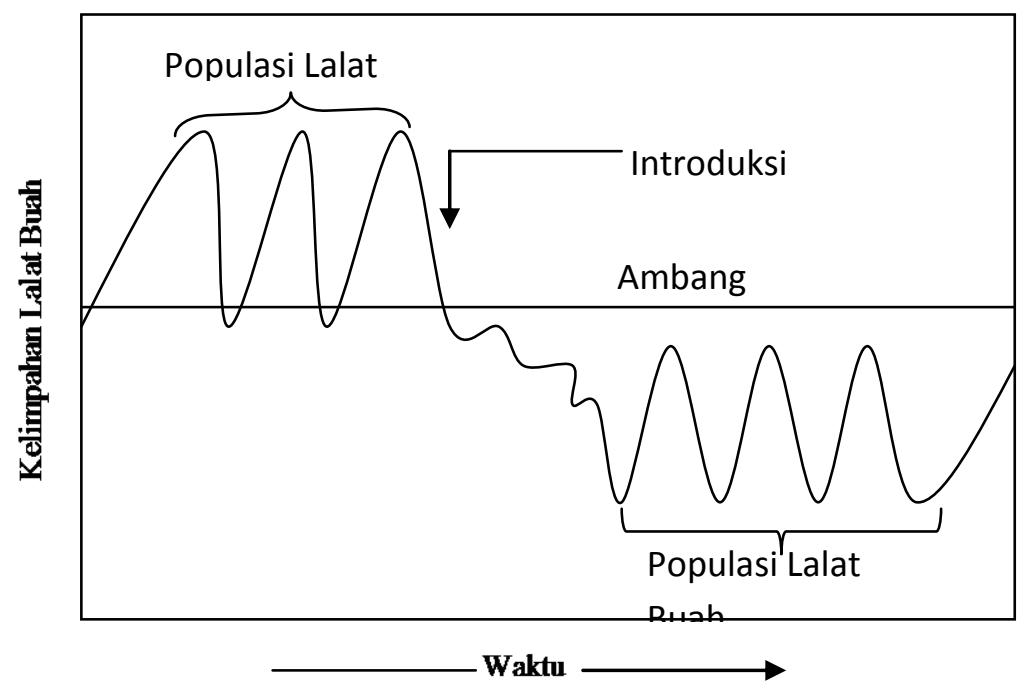

Diadopsi dari Van den Bosch et al, 1982

Gambar 2 Grafik tingkat populasi lalat buah sebagai acuan dalam introduksi parasitoi

\section{PENUTUP}

Berdasarkan hasil analisis dan pembahasan, maka dapat diambil kesimpulan bahwa: (1). Potensi parasitoid yang dapat dikembangkan di Pulau Lombok terdiri dari Biosteres vandenboschi Fullaway, Opius makii Sonan, Chalcidoidea, Eurytomide, Diapriidae dan Eulophidae. (2). Beberapa spesies parasitoid yang ditemukan di Pulau Lombok dapat menurunkan tingkat kelimpahan populasi lalat buah dari genus Bactrocera yang umum ditemukan pada buah mangga, belimbing dan jambu air. (3). Potensi parasitoid di Pulau
Lombok dapat dipertahankan bahkan ditingkat melalui mekanisme monitoring dan pengembangan parasitoid di laboratorium.

\section{SARAN}

(1). Melihat potensi yang dimiliki parasitoid dan banyaknya parasitoid yang ada di Pulau Lombok maka penggunaan parasitoid dalam pengendalian lalat buah Bactrocera perlu dilakukan sehingga dapat meningkatkan jumlah dan mutu produksi buah-buahan di Pulau Lombok, (2) Penggunaan parasitoid sebagai agen pengendali lalat buah perlu 
dilakukan untuk mengurangi resiko pencemaran lingkungan seperti yang diakibatkan oleh penggunaan insektisida, (3) Perlunya dilakukan penelitian lanjutan mengenai potensi parasitoid di Pulau Lombok sebagai pengendali lalat buah, sehingga bisa dimanfaatkan oleh masyarakat sebagai salah satu agen pengendali lalat buah yang efektif dan ekonomis.

\section{DAFTAR RUJUKAN}

Ardiasningsih, N.N. 2006. Parasitasi Lalat Buah Bactrocera yang Terdapat Pada Buah yang Diperdagangkan di Pasar Buah Narmada dan Cakranegara. Skipsi tidak diterbitkan. Mataram: FKIP Universitas Mataram.

Artayasa, I.P dan Hadiprayitno, G. 2003. Kelimpahan Populasi Lalat Buah Bactrocera Dorsalis Kompleks (Diptera : Tephritidae) Pra Dewasa Dalam Periode Pra Dan Pasca Pemangsaan Antraktan Petrogenol Di Lingsar Lombok Barat. Laporan penelitian. Mataram: FKIP Universitas Mataram.

Artayasa, I.P.1999. Potensi Parasitoid Dalam Pengendalian Lalat Buah B. Carambola Drem dan Hancock di Kebun Percobaan Buah-buahan, Subang, Jawa Barat. Tesis tidak diterbitkan. Bandung: Institut Teknologi Bandung.

Artayasa, I.P.,Hadiprayitno, G. dan Ardiasningsih, N.N. 2006. Parasitasi lalat Buah Bactrocera yang Terdapat Pada Buah di Pasar Buah Narmada dan
Cakranegara. Jurnal Pijar Mipa, Vol 2(1): 81-85.

Kuswadi. 2005.Panduan Lalat Buah, (online),

(http://www.deptan.go.id/ditlinhorti/ma $\mathrm{kalah} / \mathrm{lalat}$ buah/ttln, diakses tanggal 19 Februari 2007).

Mulyono, S. 2003. Identifikasi Spesies Lalat Buah Therpritidae pada Buah yang Diperdagangkan di Pasar Bertais Kecamatan Cakranegara Kota Mataram Tahun 2003. Skripsi tidak diterbitkan. Mataram: FKIP Universitas Mataram.

Putra, N.S. 1997. Hama Lalat Buah dan Pengendaliannya. Yogyakarta: Kanisius.

Rauhun. 2006. Spesies Dan Kelimpahan Lalat Buah Bactrocera yang Terdapat pada Buah yang Diperdagangkan di Pasar Buah Narmada dan Cakranegara. Skripsi tidak diterbitkan. Mataram: FKIP Universitas Mataram.

Subahar, T.S.S. 1999. Studi Parasitoid Lalat Buah (Dacus) sebagai Salah Satu Upaya dalam Pengendalian Hama Terpadu (PHT) Buah-Buahan. Laporan penelitian. Bandung: Institut Teknologi Bandung.

Van den bosch, R.,Messenger, P.S dan Guiterez, A.P. 1982. An Introduction to Biological Control. New York: Plenum.

Widarto, H.T. 1996. Daur Hidup Lalat Buah Bactrocera carambolae Drew \& Hancock pada Kondisi Laboratorium. Skripsi tidak diterbitkan. Bandung: Institut Teknologi Bandung. 